\title{
Expression and secretion of a biologically active glycoprotein hormone, ovine follicle stimulating hormone, by Pichia pastoris
}

\section{A E Fidler, S Lun, W Young and K P McNatty}

AgResearch Wallaceville, PO Box 40063, Ward Street, Upper Hutt, New Zealand (Requests for offprints should be addressed to A E Fidler)

\begin{abstract}
The methylotrophic yeast, Pichia pastoris, has been used to co-express recombinant genes formed by fusion of the mating factor-alpha $(\mathrm{MF} \alpha)$ leader and ovine follicle stimulating hormone (oFSH) $\alpha$ and $\beta$ subunit coding sequences. Pichia strains carrying single copies of the two fusion genes secreted recombinant oFSH (roFSH) to concentrations of approximately $51 \cdot 0 \mathrm{ng} / \mathrm{ml}$ and $17.5 \mathrm{ng} / \mathrm{ml}$, measured by RIA or in vitro bioassay respectively, whereas a strain with two copies of the $\alpha$ and one copy of the $\beta$ subunit fusion genes secreted roFSH to concentrations of $61 \mathrm{ng} / \mathrm{ml}$ (RIA) and $22 \mathrm{ng} / \mathrm{ml}$ (bioassay).
\end{abstract}

It appears that the Pichia-derived roFSH had about one-third the in vitro bioactivity of native oFSH or, alternatively, only one-third of the roFSH is bioactive. Measurements of secreted roFSH $\alpha$ and $\beta$ subunit concentrations indicated less than $10 \%$ of $\alpha$ and $25-33 \%$ of $\beta$ subunits were stably dimerized. The receptor binding properties of the roFSH resemble those of native oFSH. In summary this paper reports the production, by $P$. pastoris, of a heterodimeric glycoprotein hormone (roFSH) that has in vitro biological activity.

Fournal of Molecular Endocrinology (1998) 21, 327-336

\section{INTRODUCTION}

Follicle stimulating hormone (FSH) secreted by pituitary gonadotrophs promotes ovarian steroidogenesis and follicular growth (Richards 1994). Administration of exogenous FSH can be used to promote the maturation of multiple ovarian follicles (i.e. superovulation), a procedure that has found practical application in both human infertility treatment and animal breeding programmes (Ben-Cherit et al. 1996, De Koning et al. 1994). At present, the FSH used for the superovulation of domestic animals is purified from animal-derived material; however, the issues of raw material supply and potential pathogen transmission indicate a requirement for recombinant $\mathrm{FSH}$ (De Koning et al. 1994).

Structurally, FSH is a heterodimer formed by the non-covalent association of an $\alpha$ subunit - which is common to three pituitary glycoprotein hormones, FSH, luteinizing hormone $(\mathrm{LH})$ and thyroid stimulating hormone (TSH) (Combarnous 1992, Nagaya \& Jameson 1994) - and a hormone-specific $\beta$ subunit that confers receptor binding specificity (Combarnous 1992). The secondary structures of the $\alpha$ and $\beta$ subunits are constrained by intramolecular disulphide bonds, five in the $\alpha$ subunit and six in the $\beta$, and both subunits carry two $N$-linked carbohydrate moieties (Combarnous 1992). Variation in the carbohydrate structures results in both pituitary and serum FSH comprising a heterogeneous population of molecules varying in parameters such as receptor-binding affinity and metabolic clearance rate (Ulloa-Aguirre et al. 1995).

The methylotrophic yeast, Pichia pastoris, has been developed as an expression system for high-level production of recombinant proteins (Buckholz \& Gleeson 1991, Cregg et al. 1993). Pichia offers the features of (i) methanol-induced expression of heterologous genes integrated into the genome adjacent to the alcohol oxidase 1 ( $A O X 1)$ gene promoter, (ii) growth to high cell density in inexpensive, chemically defined media, and (iii) the capacity to carry out post-translational modifications resembling those of mammalian cells (Cregg et al. 1993). Using either native or heterologous secretion sequences, recombinant proteins can be directed into the yeast cell secretory pathway, wherein disulphide bond formation and glycosylation can occur before secretion into the 
growth media (Cregg et al. 1993). A wide range of biologically active recombinant proteins have now been produced in $P$. pastoris, including secreted proteins containing intramolecular disulphide bonds (Clare et al.1991, Vedvick et al. 1991). Furthermore, co-expression of two different genes in Pichia has resulted in the production of biologically active protein heterodimers (Kalandadze et al. 1996). The success of these experiments indicated that Pichia pastoris might be a suitable expression system for the production of biologically active recombinant ovine FSH (roFSH). This paper reports the co-expression of ovine FSH $\alpha$ and $\beta$ subunit cDNA sequences in $P$. pastoris to produce biologically active roFSH.

\section{MATERIALS AND METHODS}

\section{Choice of yeast expression system}

The original cloning procedure was designed with the objective of co-expressing ovine FSH $\alpha$ and $\beta$ subunit cDNA sequences in the budding yeast, Saccharomyces cerevisiae, using the expression vector, pYES2 (Invitrogen, San Diego, CA, USA). To this end, fusion genes were constructed with the $S$. cerevisiae mating factor-alpha $(\mathrm{MF} \alpha)$ leader sequence fused in-phase to sequences encoding the oFSH $\alpha$ and $\beta$ mature proteins, forming fusion genes MF $\alpha_{\mathrm{oFSH}} \alpha$ and MF $\alpha_{\mathrm{oFSH}} \beta$, respectively, as described in detail below. Note that, with both fusion genes, the FSH subunit mature protein coding sequences were positioned immediately $3^{\prime}$ to the two codons of the $M F \alpha$ leader sequence encoding the Lys-Arg dibasic motif recognized by the kex2 protease (Julius et al. 1984). Attempts to produce biologically active roFSH using $S$. cerevisiae were unsuccessful (A Fidler, unpublished results), leading to investigation of the yeast, Pichia pastoris, as an alternative yeast expression system.

\section{Cloning of the yeast $\mathrm{MF} \alpha$ leader sequence}

Nucleotide sequences encoding the yeast $\mathrm{MF} \alpha$ leader sequence were amplified using forward primer 5'-CCAAGCTTATGAGATTTCCTTCA ATTTTTA-3' (HindIII site underlined; remaining primer sequence corresponds to nucleotides 1-22 of Kurjan \& Herskowitz (1982)) and reverse primer 5' - GGGAATTCAGGCCTTTTATCCAAAGAT ACC- $3^{\prime}$ (EcoRI and StuI restriction sites underlined; remainder is the complement of nucleotides 255-237 of Kurjan \& Herskowitz (1982)). After HindIII and EcoRI (Boehringer Mannheim, Mannheim, Germany) digestion, the amplification products were electrophoresed through $1 \%(\mathrm{w} / \mathrm{v})$ low melting point agarose gels (FMC BioProducts,
Rockland, ME, USA), in-gel ligated into pUC18 using T4 DNA ligase (Boehringer Mannheim) and transformed into competent DH5 $\alpha$ cells. Plasmids having inserts were identified by restriction enzyme digestion and T7 Sequenase catalysed DNA sequencing (Amersham Life Science Ltd, Amersham, Bucks, UK). The resulting construct was termed $\mathrm{pUC18MF} \alpha$.

\section{Construction of fusion genes MFaoFSH $\alpha$ and MFooFSH $\beta$}

First-strand cDNA was synthesized from $5 \mu \mathrm{g}$ ovine pituitary total RNA using Superscript reverse transcriptase (Gibco BRL, Bethesda, MA, USA). The mature protein coding sequences of the oFSH $\alpha$ and $\beta$ subunits were amplified by Taq DNA polymerase (Boehringer Mannheim)-catalysed PCR: FSH $\alpha$ subunit forward primer 5'-TTTCTGATG GAGAGTTTACAATGCAGGGT-3' (nucleotides 143-172 of Bello et al. (1989)), reverse primer 5' - CCGAATTCAAATATTTAAGATTTGTGA TAA- 3 ' (EcoRI site underlined; remainder corresponding to nucleotides 439-418 of Bello et al. (1989)); FSH $\beta$ subunit forward primer 5'-AG CTGCGAGCTGACCAACATCACCATCAC3' (corresponding to nucleotides 113-141 of Mountford et al. (1989)), reverse primer 5'-CC GAATTCCTCTTTATTCTCTGATGTCACT-3' (EcoRI site underlined; remaining sequence the complement of nucleotides 449-430 of Mountford et al. (1989)). Reaction conditions were: $94{ }^{\circ} \mathrm{C}$ for $3 \mathrm{~min}, 60^{\circ} \mathrm{C}$ for $3 \mathrm{~min}, 72{ }^{\circ} \mathrm{C}$ for $5 \mathrm{~min}$, one cycle; $94{ }^{\circ} \mathrm{C}$ for $30 \mathrm{~s}, 62{ }^{\circ} \mathrm{C}$ for $1 \mathrm{~min}, 72{ }^{\circ} \mathrm{C}$ for $2 \mathrm{~min}$, 35 cycles; $72^{\circ} \mathrm{C}$ for $5 \mathrm{~min}$, one cycle. The PCR amplification products were incubated with T4 DNA polymerase (Boehringer Mannheim), to remove 3'A overhangs, digested with EcoRI, and ligated with StuI/EcoRI double-digested $\mathrm{pUC18MF} \alpha$. The sequences of the resulting HindIII-EcoRI fragments, encoding fusion genes either MF $\alpha_{o} F S H \alpha$ or MF $\alpha_{o F S H} \beta$, were confirmed by DNA sequencing (Amersham) as being free of errors introduced by $T a q$ polymerase.

\section{Subcloning of fusion genes MFaoFSHa and MFooFSH $\beta$ into pAO815 to form plasmids pAOM $\alpha$ and pAOM}

As originally constructed, the $\mathrm{MF} \alpha_{\mathrm{oFSH}} \alpha$ and MF $\alpha_{0} F S H \beta$ fusion genes were encoded on HindIII-EcoRI fragments (HindIII at $5^{\prime}$ end, EcoRI at $3^{\prime}$ end) to facilitate cloning into the $S$. cerevisiae expression vector, pYES2 (Invitrogen). To allow subcloning into the single EcoRI site of the $P$. pastoris expression vector, pAO815 (Invitrogen), EcoRI sites were required at both the 
$5^{\prime}$ and $3^{\prime}$ ends of the fusion gene sequence (Cregg et al. 1993). Such EcoRI sites were introduced by co-ligating the HindIII-EcoRI fragments encoding the MFooFSH $\alpha$ and MFooFSH $\beta$ fusion genes into the EcoRI site of pUC18, along with linker oligomers 5'-AATTCGGTACCA-3' and 5'AGCTTGGTA CCG-3' thereby introducing an EcoRI site into the $5^{\prime}$ end of each fusion gene. The resulting EcoRI fragments, encoding the two fusion genes, MF $\alpha_{\mathrm{oFSH}} \alpha$ and $\mathrm{MF} \alpha_{\mathrm{oFSH}} \beta$, were ligated into EcoRI digested, dephosphorylated pAO815, forming plasmids $\mathrm{pAOM} \alpha$ and $\mathrm{pAOM} \beta$ respectively. The orientation of the inserts with respect to the $A O X 1$ promoter was confirmed by restriction enzyme analysis and DNA sequencing.

\section{Construction of plasmids pAOM $\alpha \mathrm{M} \beta$ and $\mathrm{pAO}(\mathrm{M \alpha})_{2} \mathrm{M \beta}$}

Plasmid pAOM $\beta$ was double-digested with restriction enzymes BglII and BamHI and a $1 \cdot 9-\mathrm{kb}$ fragment, encoding the $A O X 1$ promoter, MF $\alpha_{0} F \mathrm{FH} \beta$ fusion gene and $3^{\prime} \mathrm{AOX} 1$ transcription termination sequences, was ligated into BamHIdigested, dephosphorylated $\mathrm{pAOM} \alpha$, producing plasmid $\mathrm{pAOM} \alpha \mathrm{M} \beta$. The relative orientation of the two fusion genes in $\mathrm{pAOM} \alpha \mathrm{M} \beta$ was determined by both restriction enzyme analysis and DNA sequencing. Plasmid pAOM $\alpha \mathrm{M} \beta$ was digested with BglII and BamHI and an approximately $3 \cdot 8-\mathrm{kb}$ fragment, encoding the two fusion genes, MF $\alpha_{0} \mathrm{FSH} \alpha$ and MFaoFSH $\beta$, with their transcription control sequences, was ligated into BamHI-digested, dephosphorylated $\mathrm{pAOM} \alpha$, producing plasmid $\mathrm{pAO}(\mathrm{M} \alpha)_{2} \mathrm{M} \beta$. Insert orientation was determined by restriction enzyme analysis and DNA sequencing.

\section{GS115 transformation and screening of transformants}

The Pichia host strain, GS115 (his4) (Invitrogen), was transformed with BglII-linearized plasmids using the lithium chloride method (Ausubel et al. 1994). $\mathrm{His}^{+} / \mathrm{Mut}^{\mathrm{S}}$ transformants were isolated by selection for $\mathrm{His}^{+}$auxotrophy and screening for slow growth on media containing methanol as the sole carbon source $\left(M u t^{\mathrm{S}}\right)$ (Sreekrishna \& Kropp 1996). The presence of oFSH $\alpha$ and $\beta$ subunit sequences in $\mathrm{His}^{+} / \mathrm{Mut}^{\mathrm{s}}$ transformants was confirmed by PCR from genomic DNA templates (Linder et al. 1996).

\section{Induction of recombinant protein production}

Pichia culturing and induction followed 'shake tube' and 'shake flask' procedures in which cultures were grown to high density in rich media with a glycerol carbon source and then resuspended in media containing methanol as the sole carbon source (Barr et al. 1992, Sreekrishna \& Kropp 1996). After 2 days of induction, the culture medium was clarified by centrifugation, a protease inhibitor cocktail (Complete, Boehringer Mannheim) was added and the mixture dialysed extensively against $1 \times$ phosphate buffer saline (PBS) at $4{ }^{\circ} \mathrm{C}$. Samples were stored at $-20{ }^{\circ} \mathrm{C}$ before analysis by radioimmunoassay and bioassay.

\section{Radioimmunoassays}

Immunoreactive FSH dimer and oFSH $\alpha$ were measured using RIA kits supplied by the NIH National Hormone and Pituitary Program (NIH, Bethesda, MD, USA). Samples were assayed for FSH dimer using United States Department of Agriculture (USDA)-oFSH-19-selective immunoaffinity purified (SIAFP)-I-2 for iodination, USDA-oFSH-19-SIAFP-RP-2 $(94 \times$ NIH-oFSH$\mathrm{S} 1$; biological potency $=2351 \mathrm{IU} / \mathrm{mg}$ ) for reference preparation and National Institute of Diabetes and Digestive and Kidney Diseases-anti oFSH-1 antiserum. For the assay of oFSH $\alpha$ subunit, WRR-1-Alpha was used for iodination and reference preparation, and the antiserum was National Institute of Arthritis, Metabolism and Digestive Diseases-anti-oLH Alpha-1. For the assay of oFSH $\beta$ subunit, oFSH $\beta$ (Bioscan Continental Inc., Quebec, Canada) was used for iodination and reference preparation, and the antiserum was anti-porcine FSH $\beta$ (Biogenesis Ltd, Poole, Dorset, UK). Standards were iodinated using the Chloramine $\mathrm{T}$ method and purified by gel chromatography (FSH $\alpha$ and $\beta$ subunits) or ion exchange chromatography (FSH dimer) (Moore et al. 1997). Assays were performed by incubating $100 \mu$ l sample or standard, $100 \mu \mathrm{l}$ primary antibody and $50 \mu \mathrm{l}$ tracer overnight at room temperature. Separation of free from bound hormone was by the second antibody method, using sheep anti-rabbit $\operatorname{IgG}$, followed by $1 \mathrm{ml} 6 \%$ polyethylene glycol 8000 (Carbowax Union Carbide Co., Danbury, CT, USA). Sensitivities of the assays for $\mathrm{FSH} \alpha, \mathrm{FSH} \beta$ and FSH dimer ( $90 \%$ of zero binding) were $0 \cdot 1,0 \cdot 5$ and $0 \cdot 2 \mathrm{ng} / \mathrm{ml}$ respectively. Intra- and inter-assay coefficients of variation for the above assays were $9 \%$ and $18 \cdot 8 \%, 10 \cdot 9 \%$ and $15 \cdot 4 \%$, and $7 \cdot 9 \%$ and $10 \cdot 8 \%$ respectively.

\section{Radioreceptor assay (RRA)}

Clarified supernatants from methanol-induced 'shake flask' cultures of strains GSpAO815, 
GSpAOM $\alpha \mathrm{M} \beta$ and $\operatorname{GSpAO}(\mathrm{M} \alpha)_{2} \mathrm{M} \beta$ were dialysed extensively against $10 \mathrm{mM} \mathrm{MgCl}_{2}, 50 \mathrm{mM}$ Tris- $\mathrm{HCl} \mathrm{pH} \mathrm{7.3} \mathrm{before} \mathrm{being} \mathrm{concentrated} \mathrm{tenfold}$ by ultrafiltration (Amicon, Beverly, MA, USA). FSH concentrations measured by RRA were quantified using membrane fractions from bovine testes as previously reported (Moore et al. 1997) using USDA- ${ }^{125} \mathrm{I}$ oFSH-19-SIAFP-I-2 as tracer and USDA-oFSH-19-SIAFP-RP-2 for reference preparation. Samples from methanol-induced Pichia cultures were assayed at supernatant protein concentrations of less than $30 \mu \mathrm{g}$ per tube $(300 \mu \mathrm{g} / \mathrm{ml})$ to avoid the detection of non-specific binding interference when the supernatants were assayed at higher concentrations. Total protein concentrations were determined by the bicinchoninic acid method (Pierce, Rockford, IL, USA).

\section{In vitro FSH bioassay}

The FSH bioassay, using a Chinese Hamster Ovary (CHO) cell line expressing the human FSH receptor, was essentially as described previously (Albanese et al. 1994). However, the assay endpoint was cAMP production, as measured using RIA rather than luciferase reporter gene expression. Native oFSH (NIH-FSH-RP2) (NIH) was used as the standard.

\section{RESULTS}

\section{Plasmid pAO815-based constructions and transformation into Pichia host strain GS115}

Four plasmid constructs were produced: (i) pAOM $\alpha$, encoding the MFaoFSH $\alpha$ fusion gene alone, (ii) pAOM $\beta$, encoding the MF $\alpha_{o F S H} \beta$ fusion gene alone, (iii) pAOM $\alpha \mathrm{M} \beta$, encoding both the MF $\alpha_{\mathrm{oFSH}} \alpha$ and $\mathrm{MF} \alpha_{\mathrm{oFSH}} \beta$ fusion genes in tandem, and (iv) pAO $(\mathrm{M} \alpha)_{2} \mathrm{M} \beta$, encoding two copies of the MF $\alpha_{o F S H} \alpha$ gene and a single copy of the MF $\alpha_{o F S H} \beta$ gene (Fig. 1A). In those plasmids with multiple fusion genes, each gene is transcribed from its own $A O X 1$ promoter and is separated from adjacent genes by the $3^{\prime} A O X 1$ transcription termination sequence. As it has been found that the level of recombinant protein production is frequently positively correlated with the number of copies of the corresponding gene (Sreekrishna \& Kropp 1996), plasmid pAO(M $\alpha)_{2} \mathrm{M} \beta$ was constructed to mimic more closely the stoichiometry of the $\alpha / \beta$ subunit dimerization reaction in gonadotrophs, in which the $\alpha$ subunit is present in excess of the $\beta$ subunit. Plasmids were linearized by BglII digestion and transformed into the strain GS115 (his4) (Invitrogen) and $\mathrm{Mut}^{\mathrm{S}} / \mathrm{His}^{+}$transformant strains identified. For each plasmid construct, six to ten $\mathrm{Mut}^{\mathrm{S}} / \mathrm{His}^{+}$transformants were screened for secreted recombinant protein production, and transformed strains that consistently produced the greatest amount of protein were selected for further characterization. The presence of oFSH $\alpha$ or oFSH $\beta$ cDNA sequences, or both, in the genomes of the transformed strains was confirmed by PCR using primers specific for the oFSH $\alpha$ and $\beta$ subunit sequences (Fig. 1B,C).

\section{Measurement of the concentrations of secreted recombinant oFSH $\alpha$ and $\beta$ subunits in the growth media of GS115 transformants}

RIA was used to determine the concentrations of secreted oFSH $\alpha$ and $\beta$ subunits present in the growth media of methanol-induced 'shake tube' cultures of GS115 transformants (Fig. 2). No immunoreactivity to either the anti-oFSH $\alpha$ or the anti-oFSH $\beta$ antisera was detected in the media of either untransformed GS115 (GS0) or GS115 transformed with the vector pAO815 (GSpAO815). In a representative triplicate induction, the growth media of strain GSpAOM $\alpha$ contained a mean \pm s.E.M. of $752 \pm 27 \mathrm{ng} / \mathrm{ml}$ immunoreactive oFSH $\alpha$ and no detectable oFSH $\beta$, whereas the reverse was found with strain GSpAOM $\beta$, with which immunoreactive oFSH $\beta$ was detected in the supernatant at a mean \pm s.E.M. concentration of $209 \pm 15 \mathrm{ng} / \mathrm{ml}$, with no detectable oFSH $\alpha$. These findings are consistent with the presence and absence of corresponding genes as determined by PCR (Fig. 1B,C) and confirm that there is no significant cross reaction between the two recombinant $\alpha$ and $\beta$ subunits in the RIA. Co-expression of the $\alpha$ and $\beta$ fusion genes, in strain GSpAOM $\alpha M \beta$, resulted in the secretion of recombinant oFSH $\alpha$ and $\beta$ subunits into the growth media to mean \pm s.E.M. concentrations of $547 \pm 6$ and $196 \pm 9 \mathrm{ng} / \mathrm{ml}$ respectively. The growth media of strain $\operatorname{GSpAO}(\mathrm{M} \alpha)_{2} \mathrm{M} \beta$ contained $\alpha$ subunit at a mean \pm s.E.M. concentration of $1386 \pm 174 \mathrm{ng} / \mathrm{ml}$ and oFSH $\beta$ subunit at a mean \pm S.E.M. concentration of $192 \pm 18 \mathrm{ng} / \mathrm{ml}$.

\section{RIA and bioassay measurements of the concentration of secreted recombinant oFSH dimer in the growth media of GS115 transformants}

As FSH is biologically active as an $\alpha / \beta$-subunit heterodimer, both RIA and an in vitro bioassay were used to determine the concentration of roFSH dimer present in the growth media of the transformed Pichia strains. Neither FSH immunoreactivity nor bioactivity was detected either in 


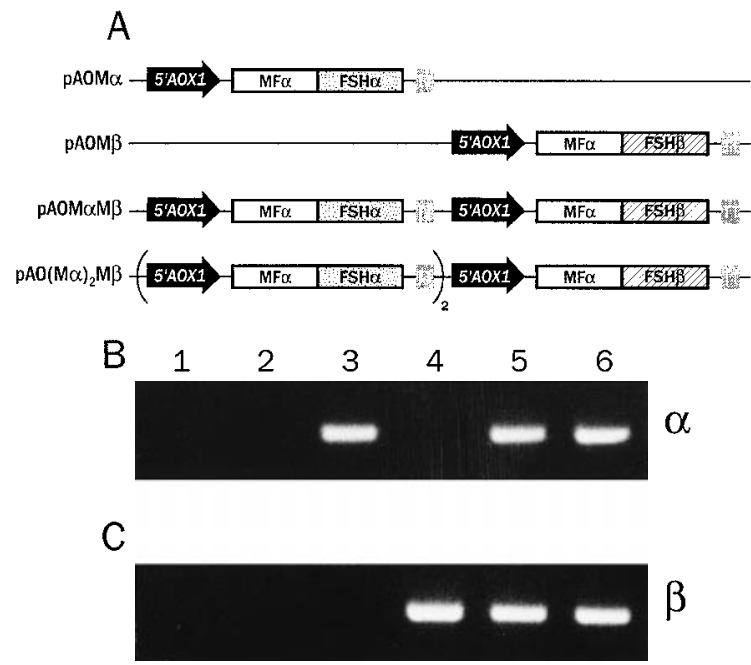

FIGURE 1. (A) Arrangement of fusion genes MF $\alpha_{0} F$ SH $\alpha$ and MF $\alpha_{0} F S H \beta$ in plasmids pAOM $\alpha$, pAOM $\beta$, pAOM $\alpha \mathrm{M} \beta$ and $\mathrm{pAO}(\mathrm{M} \alpha)_{2} \mathrm{M} \beta$. The cloning strategy is outlined in Materials and Methods. Plasmid pAOM $\alpha$ encodes the fusion gene MFooFSH $\alpha$, which consists of the $S$. cerevisiae MF $\alpha$ leader sequence fused in phase to the ovine $\mathrm{FSH} \alpha$ mature protein coding region, flanked by the $A O X 1$ promoter $\left(5^{\prime} A O X 1\right)$ and transcription termination (TT) sequences. Plasmid pAOM $\beta$ resembles pAOM $\alpha$, except that it encodes the fusion gene MFooFSH $\beta$. Plasmid pAOM $\alpha \mathrm{M} \beta$ encodes both fusion genes MFooFSH $\alpha$ and MFooFSH $\beta$, each flanked by $5^{\prime} A O X 1$ and the TT sequences and orientated with respect to each other as shown. Plasmid $\mathrm{pAO}(\mathrm{M} \alpha)_{2} \mathrm{M} \beta$ encodes two copies of the MF $\alpha$ oFSH $\alpha$ fusion gene and a single copy of the MFaoFSH $\beta$ gene, with each fusion gene being flanked by the $A O X 1$ transcription control sequences. All pAO815-derived plasmid constructs were linearized by BglII digestion before being transformed into Pichia strain GS115. Transformants in which the linearized plasmids had incorporated into the $A O X 1$ gene by homologous recombination were identified by sequentially selecting for the $\mathrm{His}^{+}$phenotype and then screening for the $\mathrm{Mut}^{\mathrm{S}}$ phenotype. The resulting $\mathrm{His}^{+} / \mathrm{Mut}^{\mathrm{S}}$ strains were designated GSpAOM $\alpha$, GSpAOM $\beta$, GSpAOM $\alpha M \beta$ and $\operatorname{GSpAO}(\mathrm{M} \alpha)_{2} \mathrm{M} \beta$. (B,C) Detection of oFSH $\alpha$ and $\beta$ subunit cDNA sequences in the genomes of transformed Pichia strains. Genomic DNAs from strains GS115 (host strain untransformed) (lane 1), GSpAO815 (host strain transformed with plasmid pAO815) (lane 2), GSpAOM $\alpha$ (lane 3), GSpAOM $\beta$ (lane 4),

GSpAOM $\alpha M \beta$ (lane 5) and $\operatorname{GSpAO}(\mathrm{M} \alpha)_{2} \mathrm{M} \beta$ (lane 6) were used as templates for PCR with primers specific to the ovine FSH $\alpha$ (B) and ovine FSH $\beta$ (C) cDNA

sequences. The PCR primers were those used to amplify the oFSH $\alpha$ and $\beta$ subunit coding regions for construction of the fusion genes and amplified products of $296 \mathrm{bp}(\mathrm{FSH} \alpha)$ and $336 \mathrm{bp}(\mathrm{FSH} \beta)$. The amplification products were electrophoresed through $2 \%$ (w/v) agarose gels, ethidium bromide-stained and photographed under u.v. illumination. the growth media of control strains, GS0 and GSpAO815, or the media of strains transformed with only one of the two fusion genes, strains GSpAOM $\alpha$ and GSpAOM $\beta$ (Fig. 3). In contrast, the growth media of Pichia strains carrying at least one copy of the $\alpha$ and $\beta$ subunit fusion genes (i.e. strains $\operatorname{GSpAOM} \alpha M \beta$ and $\operatorname{GSpAO}(\mathrm{M} \alpha)_{2} \mathrm{M} \beta$ ) secreted roFSH dimer into their growth media: GSpAOM $\alpha M \beta$ (RIA mean \pm s.E.M. concentration $50 \cdot 9 \pm 1 \cdot 4 \mathrm{ng} / \mathrm{ml}$; bioassay mean \pm s.E.M. concentration $17 \cdot 5+2.7 \mathrm{ng} / \mathrm{ml}) ; \quad \operatorname{GSpAO}(\mathrm{M} \alpha)_{2} \mathrm{M} \beta$ (RIA mean \pm s.E.M. concentration $61 \cdot 2 \pm 5 \cdot 6 \mathrm{ng} / \mathrm{ml}$; bioassay mean \pm S.E.M. concentration $21 \cdot 8 \pm 2 \cdot 4 \mathrm{ng} / \mathrm{ml}$ ) (Fig. 3).

The triplicate induction results indicated that duplication of the $\alpha$ subunit fusion gene, strain $\operatorname{GSpAO}(\mathrm{M} \alpha)_{2} \mathrm{M} \beta$, resulted in an increase in production of roFSH dimer when compared with strain GSpAOM $\alpha \mathrm{M} \beta$, which carries a single copy of the $\alpha$ subunit fusion gene. To confirm this, ten 'shake-tube' cultures of strains GSpAOM $\alpha \mathrm{M} \beta$ and $\operatorname{GSpAO}(\mathrm{M} \alpha)_{2} \mathrm{M} \beta$ were methanol-induced and the concentration of roFSH in the growth medium measured by both RIA and bioassay. The results showed a greater mean concentration of roFSH in the growth media of strain $\mathrm{GSpAO}(\mathrm{M} \alpha)_{2} \mathrm{M} \beta$ (RIA mean \pm s.E.M. concentration $63.1 \pm 2.8 \mathrm{ng} / \mathrm{ml}$; bioassay mean \pm s.E.M. concentration $22.6 \pm 1 \cdot 8 \mathrm{ng} /$ $\mathrm{ml}$ ) compared with strain GSpAOM $\alpha \mathrm{M} \beta$ (RIA mean \pm s.E.M. concentration $45 \cdot 0 \pm 1 \cdot 6 \mathrm{ng} / \mathrm{ml}$; bioassay mean \pm s.E.M. concentration $15 \cdot 3 \pm 1 \cdot 2 \mathrm{ng} /$ $\mathrm{ml}$ ), with the differences from both assays being statistically significant at the $1 \%$ level.

\section{FSH receptor binding characteristics of the secreted recombinant oFSH}

RRAs were used to compare the receptor binding characteristics of the recombinant oFSH with that of native oFSH. Radiolabelled native oFSH was competitively displaced from the bovine FSH receptor by increasing amounts of unlabelled native oFSH or increasing amounts of dialysed and concentrated culture media from methanol-induced cultures of strains GSpAOM $\alpha \mathrm{M} \beta$ and $\operatorname{GSpAO}(\mathrm{M} \alpha)_{2} \mathrm{M} \beta$ (Fig. 4). The sigmoidal displacement curves have been transformed into linear plots using the logit-log transformation. The regression lines for hormone displacement by the culture media of strains GSpAOM $\alpha \mathrm{M} \beta$ and $\operatorname{GSpAO}(\mathrm{M} \alpha)_{2} \mathrm{M} \beta$ parallelled each other, with slopes of -0.876 and -0.811 respectively, and that of native oFSH standard, slope $-0 \cdot 811$, indicating that the binding properties of the roFSH from the two strains resemble each other and that of the native oFSH. Control RRAs using the dialysed culture media from induced 


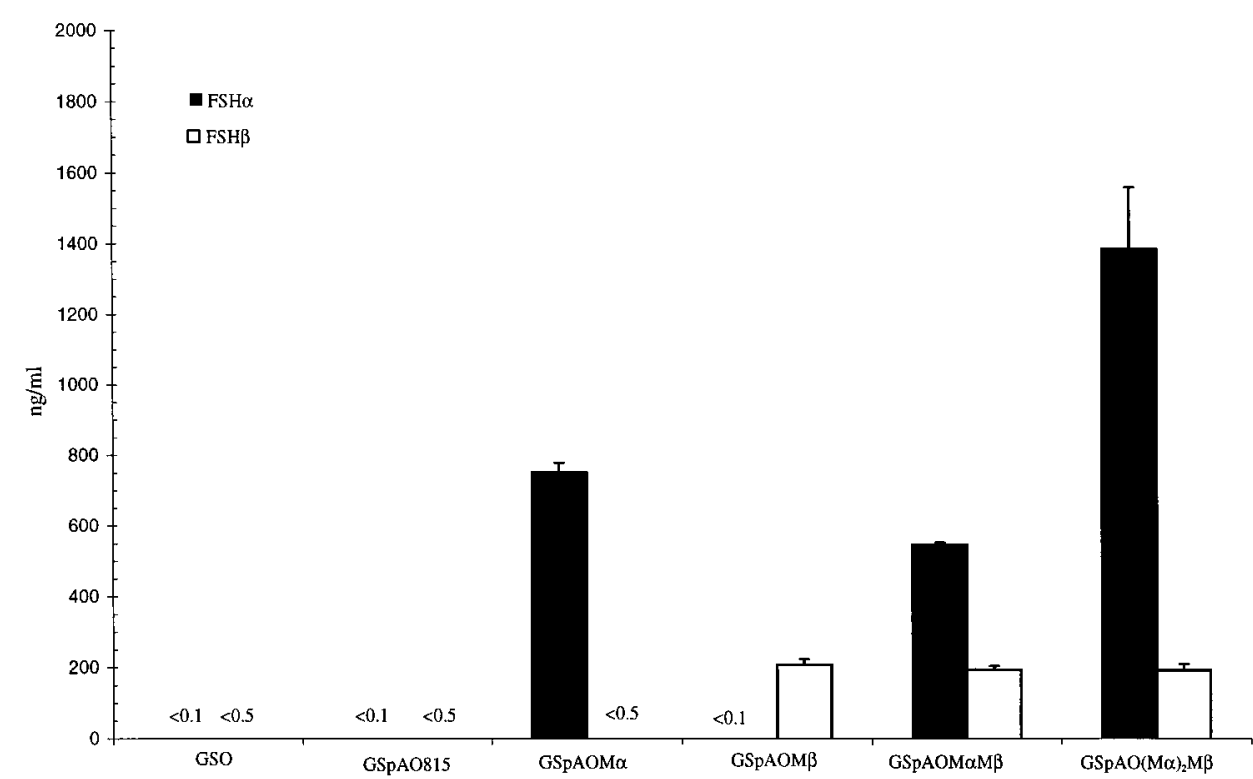

FIGURE 2. RIA measurements of the concentration of FSH $\alpha$ and $\beta$ subunits secreted into the growth media of transformed P. pastoris strains. Pichia strains GS0, GSpAO815, GSpAOM $\alpha$, GSpAOM $\beta$, GSpAOM $\alpha M \beta$ and GSpAO(M $\alpha)_{2} \mathrm{M} \beta$ were grown for 2 days before heterologous gene expression was methanol-induced for a further 2 days. The cells were pelleted by centrifugation and the clarified supernatant dialysed extensively against $1 \times$ PBS before the FSH $\alpha(\boldsymbol{\square})$ and $\beta(\square)$ subunit concentrations $(\mathrm{ng} / \mathrm{ml})$ were assayed by RIA. Values shown are means of three inductions, with S.E.M. bars indicated.

cultures of negative control strain GSpAO815 indicated that non-specific interference with native oFSH binding occurred at culture media protein concentrations greater than $300 \mu \mathrm{g} / \mathrm{ml}$ (30 ng/tube) (Fig. 4). Using $\mathrm{ED}_{50}$ values from the RRA, the concentrations of roFSH in the tenfold concentrated culture media were calculated as $230 \mathrm{ng} / \mathrm{ml}$ for strain GSpAOM $\alpha \mathrm{M} \beta$ and $342 \mathrm{ng} / \mathrm{ml}$ for $\operatorname{GSpAO}(\mathrm{M} \alpha)_{2} \mathrm{M} \beta$.

\section{DISCUSSION}

Biologically active recombinant $\mathrm{FSH}$ has been produced previously using transformed mammalian and insect cell lines and transgenic mice (Keene et al. 1989, Greenberg et al. 1991, Mountford et al. 1994, Arey et al. 1997, Hakola et al. 1997). The CHO cell-derived recombinant human $\mathrm{FSH}$ has been used successfully in infertility treatment (Devroey et al. 1993). Furthermore, it was recently reported that Pichia-expressed bovine FSH $\beta$ subunit could be combined with native bovine $\alpha$ subunit to produce biologically active FSH (Samaddar et al. 1997). Extending these approaches, we have now reported that co-expression of recombinant genes encoding the yeast MF $\alpha$ leader sequence fused to the ovine FSH $\alpha$ and $\beta$ subunit mature protein coding regions results in the secretion of biologically active recombinant ovine FSH (roFSH).

It is of interest to note that the concentration of roFSH as measured by in vitro bioassay was only about one-third of that determined by RIA, indicating either that the roFSH has one-third the biopotency of native oFSH or, alternatively, that only about one-third of the immunoreactive roFSH is biologically active. The difference in the measurements of the two assays cannot be attributed to non-specific factors within the growth media interfering with the bioassay, as native oFSH standards diluted in strain GSpAO815 growth media were accurately measured using the bioassay (data not shown). It should be borne in mind that the two assays used (RIA and bioassay) differ with respect to the end-points of measurements, with the RIA requiring interaction of the roFSH with a polyclonal antisera, whereas the bioassay requires roFSH binding to a G-protein-coupled membrane receptor, followed by cAMP synthesis (Albanese et al. 1994). The RRA measurements gave roFSH concentration estimates between those of the RIA 


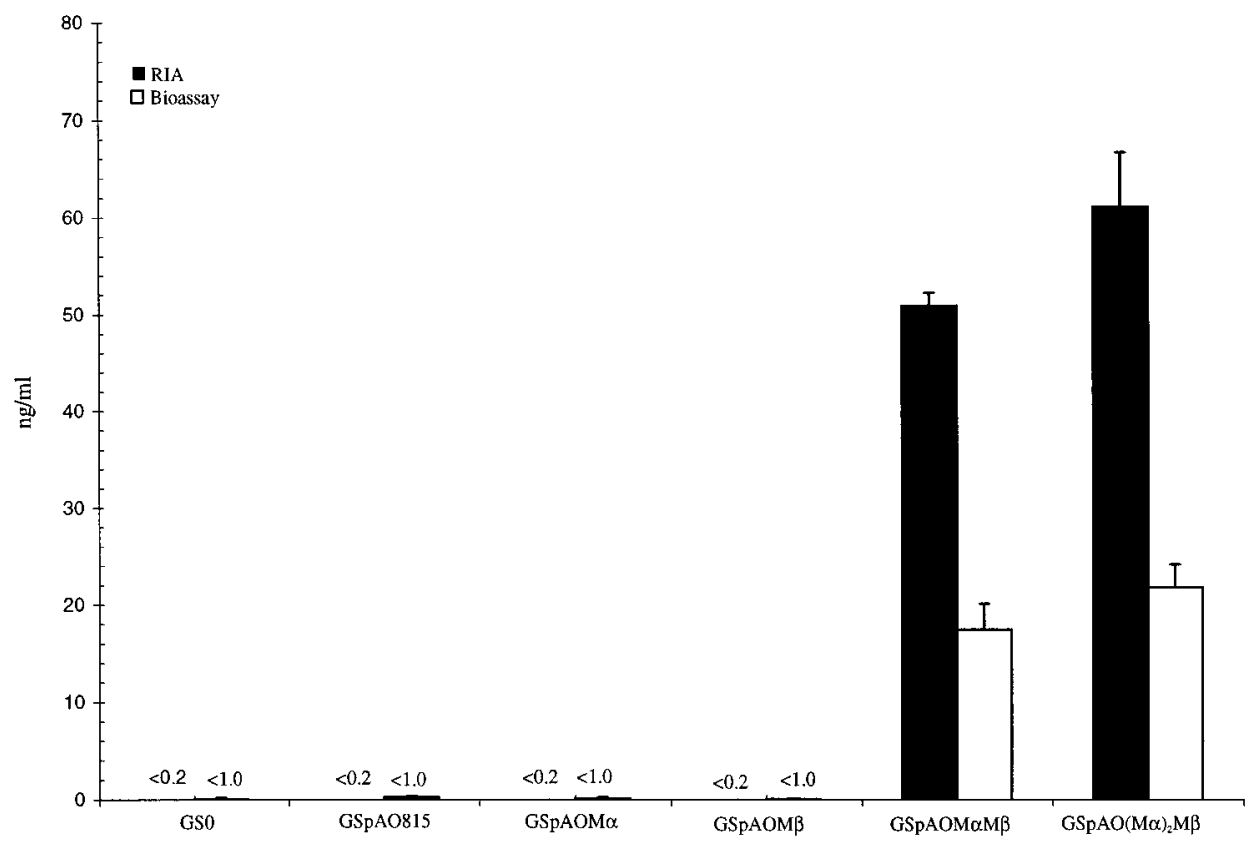

FIGURE 3. RIA and bioassay measurements of the concentration of recombinant oFSH heterodimer secreted into the growth media of transformed $P$. pastoris strains. Clarified culture supernatants from methanol-induced strains GS0, GSpAO815, GSpAOM $\alpha$, GSpAOM $\beta$, GSpAOM $\alpha M \beta$ and $\operatorname{GSpAO}(\mathrm{M} \alpha)_{2} \mathrm{M} \beta$ were dialysed against $1 \times \mathrm{PBS}$ and assayed for roFSH heterodimer by RIA ( $\square$ ) or in vitro bioassay ( $\square$ ). RIA values are the means of three inductions, the bioassay values the means of six inductions. S.E.M. bars are shown.

and the bioassay, suggesting the existence of three classes of secreted roFSH: (i) receptor-binding, biologically active, (ii) receptor-binding, biologically inactive, and (iii) non-receptor-binding. The possible lack of biological activity of two-thirds of the roFSH may result from the recombinant molecules adopting tertiary structures inappropriate for receptor binding, activation, or both. In particular, $N$-linked carbohydrate moieties significantly influence the biological activity of gonadotropins (Thotakura \& Blithe 1995, Ulloa-Aguirre et al. 1995, Arey et al. 1997), as they are required for activation of intracellular signalling pathways in addition to being determinants of in vivo bioactivity through their influence on the metabolic clearance rate (MCR) of the hormones (Ulloa-Aguirre et al. 1995, Arey et al. 1997). As the glycosylation moieties synthesized by $P$. pastoris differ from those of mammalian cells, being of the high-mannose type characteristic of yeast (Grinna \& Tschopp 1989), an important future goal will be to determine the glycosylation patterns and MCR of Pichia-derived roFSH. Comparison of the mean concentrations of the secreted roFSH $\alpha$ and $\beta$ subunits with those of the roFSH heterodimer indicates that only approximately $9 \%$ and $4 \%$ of the $\alpha$ subunits, 26 and $32 \%$ of the $\beta$ subunits, secreted by strains GSpAOM $\alpha \mathrm{M} \beta$ and $\mathrm{GSpAO}(\mathrm{M} \alpha)_{2} \mathrm{M} \beta$ respectively, are present in the culture media as dimers. Thus it would appear that dimerization of the roFSH $\alpha$ and $\beta$ subunits occurs inefficiently or the roFSH heterodimers formed are unstable, dissociating into their subunits after secretion. At the molecular level, there are a number of explanations for the low level of stable roFSH dimer formation: the 85-amino acid MFa leader sequence may sterically hinder dimerization (Kurjan \& Herskowitz 1982, Julius et al. 1984), N- and $O$-linked carbohydrate moieties may block dimerization, as has been reported for the native $\alpha$ subunit (Blithe 1990, Thotakura \& Blithe 1995), or a $\beta$ subunit intramolecular disulphide bond that forms a 'seat-belt' structure believed to be important in stabilizing gonadotrophin dimers (Lapthorn et al. 1994) may not be formed efficiently in Pichia cells.

Comparison of the $\alpha$ and $\beta$ subunit concentrations in the culture media of GS115 transformants in which the fusion genes were expressed alone, GSpAOM $\alpha$ and GSpAOM $\beta$, with those of strain 


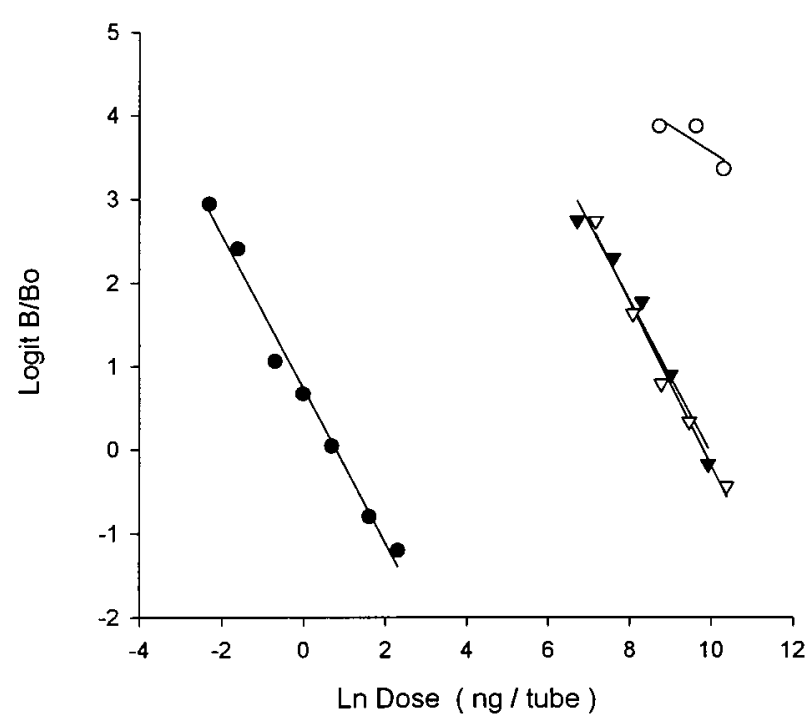

FIGURE 4. Comparative displacement of ${ }^{125}$ I-labelled oFSH from bovine FSH receptors by native oFSH and the dialysed culture media of transformed Pichia strains GSpAO815, GSpAOM $\alpha \mathrm{M} \beta$, and $\operatorname{GSpAO}(\mathrm{M} \alpha)_{2} \mathrm{M} \beta$. Radio-labelled ( $\left.{ }^{125} \mathrm{I}\right)$ oFSH (USDA-oFSH-19SIAFP-I-2) was specifically displaced from bovine FSH receptors by increasing concentrations of oFSH standards (USDA-oFSH-19-SIAFP-RP-2) (๑) and tenfold concentrated dialysed culture media from methanol-induced cultures of strains GSpAOM $\alpha \mathrm{M} \beta$

$(\boldsymbol{\nabla})$ and $\operatorname{GSpAO}(\mathrm{M} \alpha)_{2} \mathrm{M} \beta(\nabla)$. At supernatant concentrations of protein greater than $30 \mu \mathrm{g} / \mathrm{tube}$, non-specific displacement of the ${ }^{125} \mathrm{I}-\mathrm{oFSH}$ was observed using the culture media from negative control strain GSpAO815 $(\bigcirc)$. Concentrations of native oFSH standards $(\mathbf{O})$ are $\mathrm{Ln}(\mathrm{ng} \mathrm{oFSH} /$ tube) while concentrations of culture media (GSpAO815 $(\bigcirc)$, $\left.\operatorname{GSpAOM} \alpha \mathrm{M} \beta(\boldsymbol{\nabla}), \operatorname{GSpAO}(\mathrm{M} \alpha)_{2} \mathrm{M} \beta(\nabla)\right)$ are $\operatorname{Ln}(\mathrm{ng}$ total protein/tube). Logit $\mathrm{B} / \mathrm{Bo}, \log _{\mathrm{e}}(\mathrm{b} / 100-\mathrm{b})$ where $\mathrm{b}$ is the proportion of tracer bound expressed as a percentage of that in the zero standard. Values shown are the means of duplicate assays.

GSpAOM $\alpha M \beta$ indicates that $\beta$ subunit production is unaffected by co-expression of the $\alpha$ subunit gene, whereas the secreted $\alpha$ subunit concentrations are significantly reduced when co-expressed with the $\beta$ subunit gene $(P<0 \cdot 001)$. In contrast, $\alpha$ subunit production is increased by duplicating the $\mathrm{MF} \alpha \mathrm{oFSH} \alpha$ gene, the mean concentration of $\alpha$ subunit secreted by strain $\operatorname{GSpAO}(\mathrm{M} \alpha) 2 \mathrm{M} \beta$ $(1386 \mathrm{ng} / \mathrm{ml})$ being approximately double that produced by strain GSpAOM $\alpha(752 \mathrm{ng} / \mathrm{ml})$ (a difference that is statistically significant at the $5 \%$ level). Increased $\alpha$ subunit secretion with doubling of gene copy number is more dramatic when comparing strains GSpAOM $\alpha M \beta$ and $\operatorname{GSpAO}(\mathrm{M} \alpha) 2 \mathrm{M} \beta$. The more than twofold differ- ence in $\alpha$ subunit secretion between these strains may indicate that increased $\alpha$ subunit production overcomes the apparent inhibitory effect of $\beta$ subunit co-expression. Although the fraction of $\alpha$ subunit secreted by strain $\operatorname{GSpAO}(\mathrm{M} \alpha) 2 \mathrm{M} \beta$ that is dimerized with $\beta$ subunit is low at $4 \%$ (compared with $9 \%$ with strain GSpAOM $\alpha M \beta$ ), duplicating the MFaoFSH $\alpha$ gene did result in a $40-50 \%$ increase in roFSH dimer production as measured by RIA, bioassay and RRA.

As noted above, at $20-60 \mu \mathrm{g} / \mathrm{l}$, the amounts of roFSH secreted by the transformed Pichia strains are modest when compared with the $\mathrm{mg} / \mathrm{l}$ to $\mathrm{g} / \mathrm{l}$ values reported for some Pichia-produced heterologous proteins (Sreekrishna \& Kropp 1996). However, the amounts are comparable to the values of 300-400 $\mu \mathrm{g} / \mathrm{l}$ previously reported for recombinant heterodimer secretion by Pichia (Kalandadze et al. 1996). Although the low level of roFSH production may, in part, reflect the low efficiency of roFSH dimer formation, concentrations of secreted $\alpha$ and $\beta$ subunit themselves are at the lower end of the range of reported recombinant protein production by Pichia (Sreekrishna \& Kropp 1996). roFSH subunit synthesis is probably influenced by the conditions of yeast growth and induction, and by the sequences of the recombinant genes. The growth and induction procedures used in this work were standard 'shake tube' or 'shake flask' procedures, both of which produced similar concentrations of secreted recombinant proteins. However, these growth and induction conditions are by no means optimal, and the use of bioreactors frequently results in a substantial increase in heterologous protein production (Sreekrishna \& Kropp 1996). Both the nucleotide composition and codon usage of heterologous genes influence their level of expression in Pichia (Sreekrishna \& Kropp 1996). Although the $\mathrm{A}+\mathrm{T}$ content of the $\mathrm{FSH} \alpha$ and $\beta$ subunit coding sequences, $54 \%$ and $44 \%$ respectively, is within the $30-55 \%$ range considered compatible with high level expression, both the $\alpha$ and $\beta$ subunit coding sequences include one or more codons believed to be unfavourable for translation in Pichia: in the $\alpha$ subunit, GGG encoding $\mathrm{Gly}_{34}$, and in the $\beta$ subunit, GGG $\left(\mathrm{Gly}_{99}\right)$, ATA ( $\left.\operatorname{Ile}_{20}\right)$, CGC $\left(\operatorname{Arg}_{88}\right)$ and CGA ( $\operatorname{Arg}_{96}$ ) (Bello et al. 1989, Mountford et al. 1989, Sreekrishna \& Kropp 1996). Furthermore, it is possible that heterodimer formation and stability could be enhanced using fusion gene constructs encoding secretory signals other than the $\mathrm{MF} \alpha$ leader sequence. In addition, heterodimer formation and stability might be enhanced by cloning of the $\beta$ and $\alpha$ subunit coding regions in tandem, to produce a biologically active single polypeptide, as has been reported for human FSH 
expressed by mammalian cells (Sugahara et al. 1996a,b).

In summary, the key finding of this paper is that biologically active recombinant ovine follicle stimulating hormone has been produced by Pichia pastoris. To our knowledge, this is the first report of the production of a biologically active glycoprotein hormone using this particular yeast. Further studies will be needed to evaluate whether yields of $P$. pastoris-derived roFSH can be increased, and whether the roFSH is biologically active in vivo.

\section{ACKNOWLEDGEMENTS}

Our thanks go to Dr Chip Albanese for the generously providing the transformed $\mathrm{CHO}$ cellline used in the FSH bioassay, to Drs David Tisdall and Lloyd Moore for helpful comments on this manuscript, and to Alan Barkus and Ruth Kiel for assistance with figure preparation. This work was financially supported by the New Zealand Foundation for Research, Science and Technology (FoRST).

\section{REFERENCES}

Albanese C, Christin-Maitre S, Sluss PM, Crowley WF \& Jameson JL 1994 Development of a bioassay for FSH using a recombinant human $\mathrm{FSH}$ receptor and a cAMP responsive luciferase reporter gene. Molecular and Cellular Endocrinology 101 211-219.

Arey BJ, Stevis PE, Deecher DC, Shen ES, Frail DE, Negro-Vilar A \& Lopez FJ 1997 Induction of promiscuous $\mathrm{G}$ protein coupling of the follicle-stimulating hormone (FSH) receptor: a novel mechanism for transducing pleiotropic actions of FSH isoforms. Molecular Endocrinology 11 517-526.

Ausubel FM, Brent R, Kingston RE, Moore DD, Seidman JG, Smith JA \& Struhl K (Eds) 1994 Saccharomyces cerevisiae. In Current Protocols in Molecular Biology, vol 2, ch 13,

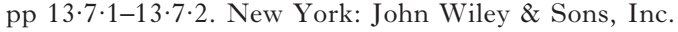

Barr KA, Hopkins SA \& Sreekrishna K 1992 Protocol for efficient secretion of HSA developed from Pichia pastoris. Pharmaceutical Engineering 12 48-51.

Bello PA, Mountford PS, Brandon MR \& Adams TE 1989 Cloning and DNA sequence analysis of the cDNA for the common $\alpha$-subunit of the ovine pituitary glycoprotein hormones. Nucleic Acids Research 1710494.

Ben-Cherit A, Gotlieb L, Wong PY \& Casper RF 1996 Ovarian response to recombinant human follicle-stimulating hormone in luteinizing hormone-depleted women: examination of the two cell, two gonadotropin theory. Fertility and Sterility 65 711-717.

Blithe DL $1990 N$-linked oligosaccharides on free $\alpha$ interfere with its ability to combine with human chorionic gonadotropin- $\beta$ subunit. Fournal of Biological Chemistry 265 21951-21956.

Buckholz RG \& Gleeson MAG 1991 Yeast systems for the commercial production of heterologous proteins. Biotechnology 9 1067-1072.
Clare JJ, Romanos MA, Rayment FB, Rowedder JE, Smith MA, Payne MM, Sreekrishna K \& Henwood CA 1991 Production of mouse epidermal growth factor in yeast: high-level secretion using Pichia pastoris strains containing multiple gene copies. Gene 105 205-212.

Combarnous Y 1992 Molecular basis of the specificity of binding of glycoprotein hormones to their receptors. Endocrine Reviews 13 670-691.

Cregg JM, Vedvick TS \& Raschke WC 1993 Recent advances in the expression of foreign genes in Pichia pastoris. Biotechnology 11 905-910.

De Koning WJ, Walsh GA, Wrynn AS \& Headon DR 1994 Recombinant reproduction. Biotechnology 12 988-992.

Devroey P, Mannaerts B, Smitz J, Coelingh Bennink H \& Steirteghem A 1993 First established pregnancy and birth after ovarian stimulation with recombinant human follicle stimulating hormone (Org 32489). Human Reproduction 8 863-865.

Greenberg NM, Anderson JW, Hsueh AJW, Nishimori K, Reeves JJ, DeAvila DM, Ward DN \& Rosen JM 1991 Expression of biologically active heterodimeric bovine follicle-stimulating hormone in milk of transgenic mice. Proceedings of the National Academy of Sciences of the USA 88 8327-8331.

Grinna LS \& Tschopp JF 1989 Size distribution and general structural features of $N$-linked oligosaccharides from the methylotrophic yeast, Pichia pastoris. Yeast $\mathbf{5}$ 107-115.

Hakola K, Van der Boogaart P, Mulders J, de Leeuw R, Schoonen W, Van Heyst J, Swolfs A, Van Casteren J, Huhtaniemi I \& Kloosterboer H 1997 Recombinant rat follicle-stimulating hormone; production of Chinese hamster ovary cells, purification and functional characterization. Molecular and Cellular Endocrinology 127 59-69.

Julius D, Schekman R \& Thorner J 1984 Glycosylation and processing of prepro- $\alpha$-factor through the yeast secretory pathway. Cell 36 309-318.

Kalandadze A, Galleno M, Foncerrada L, Strominger JL \& Wucherpfennig KW 1996 Expression of recombinant HLA-DR2 molecules. Replacement of the hydrophobic transmembrane region by a leucine zipper dimerization motif allows the assembly and secretion of soluble DR alpha beta heterodimers. Fournal of Biological Chemistry 271 20156-20162.

Keene JL, Matzuk MM, Otani T, Fauser BCJM, Galway AB, Hsueh AJW \& Boime I 1989 Expression of biologically active human follitropin in Chinese hamster ovary cells. Fournal of Biological Chemistry 264 4769-4775.

Kurjan J \& Herskowitz I 1982 Structure of a yeast pheromone gene $(M F \alpha)$ : a putative $\alpha$-factor precursor contains four tandem copies of mature $\alpha$-factor. Cell 30 933-943.

Lapthorn AJ, Harris DC, Littlejohn A, Lustbader JW, Canfield RE, Machin KJ, Morgan FJ \& Isaacs NW 1994 Crystal structure of human chorionic gonadotropin. Nature 369 455-461.

Linder S, Schliwa M \& Kube-Granderath E 1996 Direct PCR screening of Pichia pastoris clones. BioTechniques 20 980-982.

Moore LG, Ng-Chie W, Lun S, Lawrence SB, Young W \& McNatty KP 1997 Follicle-stimulating hormone in the brushtail possum (Trichosurus vulpecula): purification, characterization, and radioimmunoassay. General and Comparative Endocrinology 106 30-38.

Mountford PS, Bello PA, Brandon MR \& Adams TE 1989 Cloning and DNA sequence analysis of the cDNA for the precursor of ovine follicle stimulating hormone $\beta$-subunit. Nucleic Acids Research 176391. 
Mountford PS, Brandon MR \& Adams TE 1994 Expression and characterization of biologically active ovine FSH from mammalian cell lines. Fournal of Molecular Endocrinology 12 71-83.

Nagaya T \& Jameson JL 1994 Structural features of the glycoprotein hormone genes and their encoded proteins. In The Pituitary Gland, pp 63-89. Ed H Imura. New York: Raven Press.

Richards JS 1994 Hormonal control of gene expression in the ovary. Endocrine Reviews 15 725-751.

Samaddar M, Catterall JF \& Dighe RR 1997 Expression of biologically active beta subunit of bovine follicle-stimulating hormone in the methylotrophic yeast Pichia pastoris. Protein Expression and Purification 10 345-355.

Sreekrishna K \& Kropp KE 1996 Pichia pastoris. In Nonconventional Yeasts in Biotechnology. A Handbook, pp 203-253. Ed K Wolf. Berlin: Springer Verlag.

Sugahara T, Grootenhuis PDJ, Sato A, Kudo M, BenMenahem D, Pixley MR, Hsueh AJW \& Boime I $1996 a$ Expression of biologically active fusion genes encoding the common $\alpha$ subunit and either the CG $\beta$ or $\mathrm{FSH} \beta$ subunits: role of a linker sequence. Molecular and Cellular Endocrinology 125 71-77.

Sugahara T, Sato A, Kudo M, Ben-Menahem D, Pixley MR, Hsueh AJW \& Boime I $1996 b$ Expression of biologically active fusion genes encoding the common alpha subunit and the follicle-stimulating hormone beta subunit. Role of a linker sequence. Fournal of Biological Chemistry 271 10445-10448.

Thotakura NR \& Blithe DL 1995 Glycoprotein hormones: glycobiology of gonadotrophins, thyrotrophin and free $\alpha$ subunit. Glycobiology 5 3-10.

Ulloa-Aguirre A, Midgley AR Jr, Beitins IZ \& Padmanabhan V 1995 Follicle-stimulating isohormones: characterization and physiological relevance. Endocrine Reviews 16 765-787.

Vedvick T, Buckholz RG, Engel M, Urcan M, Kinney J, Provow S, Siegel RS \& Thill GP 1991 High-level secretion of biologically active aprotinin from the yeast Pichia pastoris. Fournal of Industrial Microbiology 7 197-202.

RECEIVED 5 June 1998 